\title{
Justiça do Trabalho e demandas coletivas: fragmentos
}

\section{LABOUR JUSTICE AND COLLECTIVE DEMANDS: FRAGMENTS}

\author{
Sayonara Grilo Continho Leonardo da Silva *
}

Resumo: O presente texto explora a temática da Justiça do Trabalho na solução de conflitos nas demandas coletivas, de que forma os Tribunais atuam frente a essas questões e como se desenvolveu a jurisprudência ao longo do tempo. Neste ensaio, buscamos apresentar elementos que agreguem às reflexões em torno da temática Justiça do Trabalho e Ações Coletivas, sendo estas analisadas de forma geral. Após a análise histórica, apresentaremos a reforma do judiciário no sentido de abertura da Justiça do Trabalho para as demandas coletivas e, por fim, como forma de exemplificar todo o exposto, citaremos casos de demandas coletivas contemporâneas.

Palavras-Chave: Justiça do trabalho, dissídios coletivos, solução dos conflitos, demandas coletivas contemporâneas.

Abstract: This paper explores the theme of the Labour Court in resolving conflicts in the collective demands, how the courts work ahead on these issues and how the law has developed over time. In this essay we present elements that add to the reflections around the theme Justice Labour and Class Actions, which are analyzed in general. After analyzing historical, present the reform of the judiciary in the direction of opening of the Labor Court for the collective demands and, finally, as a way to illustrate all the above cases will cite contemporary collective demands.

* Graduada em Ciências JurídiKeywords: Justice of labor, collective bargaining, conflict resolution, collective demands contemporary.

e Sociais pela Universida de Federal do Rio de Janeiro (1991); Mestre em Teoria do Estado e Direito Constitucional pela Pontifícia Universidade Católica do Rio de Janeiro (1996); Doutora em Ciências Jurídicas pela Pontifícia Universidade Católica do Rio de Janeiro e Professora Adjunta da Universidade Federal do Rio de Janeiro. E-mail: sayonaragrillosilva@gmail.com 


\section{INTRODUÇÃO}

A atuação dos tribunais é um campo muito profícuo de estudo e importante para a definição do conteúdo dos direitos. Crescem as pesquisas que procuram compreender a atuação dos Tribunais sob a perspectiva da judicialização da política e das relações sociais, bem como no que se refere às conexões entre sindicatos e trabalhadores com o judiciário trabalhista. No âmbito de uma sociologia do direito, estudos sobre as ideologias que estruturam a magistratura e o comportamento dos juízes remontam à década de 1960 e se ampliaram substancialmente nos últimos anos, com enfoque voltado à compreensão do funcionamento institucional do Judiciário. Agregando elementos da filosofia e da teoria do Direito, bem como da ciência política, a compreensão dos tribunais como lócus de poder político e de definição normativa redimensionou as análises sobre o papel do poder judiciário nas democracias contemporâneas.

O Judiciário também não permanece ao largo dos estudos na área da economia, seja sob as perspectivas mais liberais, com análises que privilegiam o exame dos impactos do sistema judiciário no funcionamento do mercado (Pinheiro, 2005), seja sob uma ótica que prioriza o estudo das relações de trabalho como campo multidisciplinar por excelência (Horn e Cotanda, 2011).

No Brasil, ampliam-se as investigações interdisciplinares sobre a magistratura trabalhista e a Justiça do Trabalho. Nos últimos 10 anos, no campo da sociologia do trabalho destacam-se as relevantes contribuições oriundas de importantes centros universitários, dentre os quais destacamos, no Rio de Janeiro, o antigo IUPERJ, com Werneck Vianna (2010) e a equipe do CEDES - Centro de Estudos de Direito e Sociedade sob o enfoque da judicialização (Carelli, 2011; Casagrande; Perissé, 2007; Casagrande, 2008) e com Adalberto Moreira Cardoso (2002) sobre relações de classe e a judicialização dos conflitos individuais de trabalho; na UFRJ, no PPGSA e AMORJ, com as pesquisas de Elina Pessanha e Regina Morel $(2005,2010)$ sobre perfil e posicionamentos da magistratura trabalhista brasileira, de Ângela Castro Gomes e Elina Fonte Pessanha sobre a trajetória de juízes (2010); na UFF, no Programa de Pós Graduação em Direito e Sociologia, com os trabalhos de Joaquim Leonel Alvim e Roberto Fragale Filho (1999).

No campo da ciência política, aos estudos realizados no Programa de Pós Graduação da UFSCAR, de enfoque institucionalista, sobre o processo de construção das normas e definição dos direitos pela atuação no âmbito de um sistema legislado (Noronha, 2000) e por força dos atores judiciais e profissionais 
do direito (Artur, 2007, 2010, Freitas, 2011), somam-se trabalhos recentes no campo da judicialização da política e também de uma sociologia do campo jurídico, como a realizada por Fabiano Engelmann (2006). No campo da economia do trabalho, destacam-se as pesquisas realizadas no CESIT/Unicamp e por Carlos Henrique Horn (2006) na UFRGS sobre negociação coletiva e justiça do trabalho.

Apesar do esforço desenvolvido nas últimas décadas para compreender analiticamente a Justiça do Trabalho, sua atuação, tendências ideológicas e jurisprudenciais, tais pesquisas apenas se iniciam no país, trazendo dificuldades adicionais. Neste ensaio, buscamos apresentar elementos que agreguem às reflexões em torno da temática Justiça do Trabalho e Ações Coletivas. Exclusivamente para os fins deste artigo utilizaremos a locução "ações coletivas" como um conceito amplo, gênero que envolve diversas espécies, e que compreende tanto os dissídios coletivos - de natureza econômica e de natureza jurídica - quanto as reclamações trabalhistas movidas por Sindicados e Associações Profissionais, ações de cumprimento e Ações Civis Públicas, interpostas pelo Ministério Público do Trabalho e por entidades sindicais e associativas.

Optando pelo gênero, será possível trazer fragmentos das relações entre sindicatos e Judiciário trabalhista nos primeiros quarenta anos de institucionalização deste ramo especializado, com o exame da conformação do poder normativo nas décadas de 1940, 1950, 1960 e 1970. Nesta seção (2.1.), o debate se concentrará nos dissídios coletivos, embora já existissem as chamadas ações de cumprimento das sentenças normativas. Na segunda parte do item 2, aos clássicos dissídios, se agregarão notícias sobre outras modalidades de ações coletivas. Na seção 2.2, apresentaremos elementos que permitam visualizar as ações coletivas e plúrimas que versavam sobre insalubridade, periculosidade e reajustes salariais, e produziram novos desafios à Justiça do Trabalho no bojo da redemocratização política e renovação do sindicalismo. Na década perdida para a concretização da Constituição, serão examinadas as restrições judiciais à atuação coletiva dos sindicatos por meio da limitação à substituição processual das categorias pelas entidades, ou por força da restrição aos dissídios coletivos (seção 2.3). Encerrando o percurso histórico, analisamse os anos de reconstrução e de reforma (do judiciário), com uma abertura de parte da Justiça do Trabalho às demandas coletivas. E, por fim, nestes fragmentos sobre Justiça do Trabalho e Demandas Coletivas, citaremos casos ilustrativos das demandas coletivas contemporaneamente propostas. 


\section{ESCORÇO NOS 70 ANOS}

O debate em torno da coletivização dos interesses na Justiça do Trabalho seguia tradicionalmente a grande dicotomia estabelecida na Consolidação das Leis do Trabalho entre dissídios individuais e dissídios coletivos, estes voltados para a criação de regras e condições laborais ou interpretação e aplicação erga omnes de norma jurídica preexistente. A singularidade da Justiça do Trabalho, por sua vez, se afirmava com a existência da prerrogativa normativa, exercitada por meio dos dissídios coletivos. Daí porque não causa espanto a singela afirmação de D'Araújo (2003, p.232), de que há uma polarização em torno da Justiça do Trabalho. De um lado, seus críticos enfatizaram que a atuação normativa teria impedido a negociação direta sob o argumento de que a delegação ao Judiciário das funções de fixação normativa esvaziara a possibilidade de crescimento da negociação coletiva no país. Cardoso minimiza a discussão e afirma que o recurso à Justiça do Trabalho não é um ex-ante da negociação, apenas um recurso ou meio disponível às partes, não havendo que se falar em uma centralidade na utilização dos dissídios coletivos como mecanismo de definição ou inibição das negociações coletivas (2003).

Os poucos trabalhos que examinam o conteúdo das decisões em dissídios coletivos ao longo dos últimos 70 anos sinalizam para uma ausência de uniformidade na atuação do poder normativo. Se continuidade houver será exatamente aquela de adequar-se e adaptar-se às conjunturas econômicas e políticas com a flexibilidade almejada pelos seus criadores e anunciada por Oliveira Viana (1938), desde os anos 1930, ainda que tal comportamento possa decorrer de influências internas e intrínsecas ao campo do Direito.

Atribuir significado aos significantes textuais da lei, compondo a norma jurídica no processo de decisão, contribui para a estruturação do mercado de trabalho, campo em que se desenvolvem as relações laborais. Assim, o poder normatizador, denominado por Karen Artur (2010) de o novo poder normativo da Justiça do Trabalho, está presente em todo processo cognitivo e decisório. Afinal, "Justiça do Trabalho não se reduz a poder normativo, nem mesmo quando se trata de Relações Coletivas de Trabalho, pois sua atuação estritamente jurisdicional também pode contribuir para ampliar ou diminuir os recursos de poder à disposição dos atores coletivos" (Silva, 2008). Observavase certa tendência de limitar as ações coletivas e o recurso ao judiciário aos mecanismos clássicos e corporativos de solução de conflitos coletivos de interesse, como o dissídio coletivo. Em certos momentos, opera-se certa 
confusão conceitual, que embaralha de maneira inadequada a atuação jurisdicional da Justiça do Trabalho com o exercício do poder normativo e que, por vezes, leva a identificar de modo inadequado a atuação da Justiça do Trabalho com corporativismo.

\subsection{As primeiras décadas de dissídios coletivos}

No início do século passado, a Justiça do Trabalho se singularizava como um dos mecanismos criados para conter os conflitos coletivos de trabalho, canalizando-os para "soluções" controladas, mediadas ou decididas pelo Estado, inicialmente identificado com o Poder Executivo brasileiro, diante da natureza originalmente administrativa da instituição. A coletivização de interesses e a submissão dos conflitos do trabalho às regras e formalidades de um direito processual em construção por meio dos dissídios coletivos e da atuação normativa da Justiça do Trabalho, em suas origens inscrevem as ações judiciais coletivas no ideário de um corporativismo em consolidação nos anos 1930. Em 1943, mantida a estrutura da Justiça do Trabalho na órbita administrativa, a Consolidação das Leis do Trabalho - CLT reservava individualmente a cada trabalhador a prerrogativa de requerer judicialmente o cumprimento das sentenças normativas. Os sindicatos não tinham legitimidade para propor as ações de cumprimento, demandas judiciais típicas. A coletivização dos interesses e dos conflitos de direito se circunscrevia à seara administrativa por meio dos dissídios coletivos.

A Constituição de 1946 incorporou a Justiça do Trabalho à estrutura do Poder Judiciário e criou o Tribunal Superior do Trabalho e os Tribunais Regionais do Trabalho, em substituição às instâncias precedentes. Atribuiu a possibilidade de estabelecimento de normas nos julgamentos de dissídio coletivos. Reservou, no entanto, à lei ordinária a possibilidade de especificar os casos em que as decisões poderiam estabelecer condições de trabalho. Tal constitucionalização da Justiça do Trabalho e de seu poder normativo foi inserida na Constituição de 1946, e não se viu um debate como aquele que opusera liberais e corporativos na década de 1930. A adaptação da CLT promovida pelo Decreto-Lei $9.797 / 46$ - aos preceitos constitucionais não chegou ao ponto de regulamentar o $\S 2^{\circ}$ do artigo 123, da Constituição, para determinar os casos em que o poder normativo da Justiça do Trabalho poderia ser utilizado. Desse modo, embora durante os trabalhos constituintes a inclusão do poder normativo da Justiça do Trabalho não tenha despertado maiores 
polêmicas, a partir da segunda metade da década de 1940 se travaria um amplo debate jurisprudencial em torno do tema.

Em um ambiente de afirmação institucional da Justiça do Trabalho enquanto ramo do poder Judiciário, no final dos anos 1940 houve uma interpretação expansiva do poder normativo, com o exercício da prerrogativa determinando reajustamentos salariais, mesmo na ausência de lei ordinária regulamentadora (Silva, 2008, p.185/188). Os reajustes salariais deferidos seriam mitigados com o acolhimento de argumentos empresariais relacionados ao absenteísmo. Recebido pela doutrina do Direito do Trabalho como um momento de afirmação do poder normativo, o debate girava em torno da inclusão, nas sentenças normativas, de cláusulas de assiduidade, bem como da exclusão dos efeitos subjetivos da sentença dos trabalhadores admitidos após o ajuizamento do processo de dissídio coletivo.

Nesse contexto, a resistência empresarial em reajustar os salários determinados pela Justiça do Trabalho e o acolhimento de cláusulas de assiduidade, pelo Tribunal Superior do Trabalho, para limitar os aumentos salariais concedidos pelos Tribunais Regionais, são alguns dos aspectos explicativos a serem considerados na análise dos movimentos paredistas ocorridos no Brasil em 1953 (Oliveira, 2002, p.130). Os efeitos perversos das sentenças normativas que condicionavam o pagamento do reajuste salarial à assiduidade do empregado não foram recebidas com passividade entre os trabalhadores. A resistência dos trabalhadores e as críticas à jurisprudência majoritária desaguaram no Legislativo e dois anos depois foi promulgada a Lei 2.510, de 26 de junho de 1955, que estabeleceu "ser defeso à Justiça do Trabalho, no julgamento dos dissídios coletivos, incluir, entre as condições para que o empregado perceba o aumento de salário, cláusula relativa à assiduidade ou frequência ao serviço." (Art. $1^{\circ}$ ).

Recebida pela Justiça do Trabalho como uma limitação indevida de seu poder normativo, a Lei 2.510 foi realmente a primeira norma infraconstitucional de regulamentação do poder normativo. Indica, sem sombra de dúvidas, um dos principais temas na pauta das ações coletivas e demandas dos trabalhadores perante a Justiça do Trabalho nos anos 1950. Isso sem contar, é claro, com as demandas pelo cumprimento das decisões proferidas em dissídio coletivo por efetivação imediata dos reajustes deferidos pelos Regionais e pela "perversidade de alguns julgamentos dos tribunais do trabalho (French, 2001, p.21).

Digno de registro o comportamento dos Tribunais diante da eclosão da conhecida "greve dos 400 mil", em 1957. Em uma época em que ao descumprimento das determinações de reajuste salarial disseminado entre o 
empresariado nacional e ao longo tempo de tramitação dos recursos interpostos em dissídios coletivos, cujas decisões regionais não eram exigíveis, deve-se acrescentar a postura do Tribunal Superior do Trabalho de acolher os pleitos das empresas, suprimindo ou reduzindo reajustes deferidos pelos Tribunais Regionais.

Para melhor compreensão dos percalços vivenciados pelos trabalhadores em suas demandas coletivas, abrem-se parênteses para explicitar que pela natureza jurídica da sentença normativa (vide nota 15 supra) os processos de dissídios coletivos criam normas jurídicas (como, por exemplo, a determinação de um reajuste salarial), mas tais processos de dissídios não se prestam a exigir do empregador o cumprimento da decisão. Assim, apesar da coletivização dos interesses presente na sentença normativa por meio dos dissídios coletivos, as sentenças normativas não eram objeto de cumprimento/execução coletiva. Assim como o contemporâneo debate sobre a legitimação dos sindicatos para executar as decisões em ações coletivas e civis públicas, também nos primórdios do processo de coletivização de interesses havia uma individualização da execução. Como a sentença normativa, apesar de oriunda de uma "ação coletiva" se cinge a estabelecer normas abstratas e genéricas, e como a lei, voltada em sua maioria à regulação do setor econômico e não à empresa particular, após seu término, deveriam os trabalhadores individualmente postular em juízo o

cumprimento da decisão normativa por seu empregador. Apesar da lacuna em torno do tema, foi no ambiente dos conflitos coletivos da década de 1950 que as ações coletivas, em sentido estrito, ingressam no Direito brasileiro. Em um contexto de descumprimento disseminado de decisões proferidas em dissídios coletivos, foi necessário reformar a lei para atribuir aos sindicatos a legitimidade ativa para postular em juízo o cumprimento das sentenças normativas. Como já vimos, em sua origem, a CLT estabelecia a distinção entre dissídios individuais e coletivos, mas reservava aos trabalhadores a legitimidade para demandar contra seu empregador as diferenças salariais e o cumprimento das decisões coletivas obtidas pelos sindicatos nos dissídios coletivos. Somente em 1954, com a Lei n ${ }^{\circ} 2.275$, de 30 de julho, seria atribuído aos sindicatos a propositura das ações de cumprimento. Inaugura-se, no Direito brasileiro, a ação coletiva em sentido estrito com a reforma do parágrafo único do Artigo 872 da CLT. À redação original do Artigo 872 da CLT ("Celebrado o acordo, ou transitada em julgado a decisão, seguir-se-á o seu cumprimento, sob as penas estabelecidas neste Título." Parágrafo único. "Quando os empregadores deixarem de satisfazer o pagamento de salários na conformidade 
da decisão proferida, poderão os empregados, juntando certidão de tal decisão, apresentar reclamação à Junta ou Juízo competente, observado o processo previsto no capítulo III deste título, sendo vedado, porém, questionar sobre a matéria de fato e de direito já apresentada na decisão") foi acrescida, pela Lei 2.275 de 1954, a locução "poderão os empregados ou seus sindicatos, independentes de outorga de poderes de seus associados", redação vigente até os dias atuais.

Pela nova regra, além do empregado, o Sindicato representaria em juízo seus associados, independentemente de autorização expressa, passando a deter legitimidade ativa para postular em seu nome o direito dos associados, visando a obter o cumprimento das cláusulas fixadas em dissídios coletivos descumpridos pelas empresas. Inicia-se no Direito brasileiro a legitimação ativa e as ações coletivas em sentido estrito, mecanismo por excelência para obter o cumprimento das normas coletivas.

No âmbito dos dissídios coletivos, nas décadas de 1960 e 1970 muito se discutiu sobre a introdução da política salarial, com as novas regras de contenção remuneratória impostas pela ditadura militar. Segundo Acker, além das dramáticas restrições à greve, o regime militar "investiu decididamente contra o poder normativo e as negociações coletivas, subordinando-os a um "disciplinamento econômico" garantidor de um pretenso desenvolvimento que teve sua exacerbação ufanista no 'milagre brasileiro'." (Acker, 1986, p.48-49). Como uma das consequências, desloca-se a postulação dos sindicatos nos dissídios coletivos até então voltada para a efetivação dos direitos existentes e para a manutenção e melhoria do nível salarial dos trabalhadores. Segundo Ana Acker (1986), a violência institucionalizada e o agravamento das condições de vida dos trabalhadores teriam levado "os sindicatos de empregados a se voltarem para a via jurisdicional" e ampliado o escopo temático das demandas submetidas ao Tribunal. Segundo pesquisa realizada por Paola Cappellin (2012), foi exatamente na década de 1960, por exemplo, que as telefonistas da Embratel conquistaram a redução da penosa jornada de trabalho por meio de julgamento de processo de dissídio coletivo.

Além das ações de cumprimento dos direitos obtidos nos dissídios coletivos, em 1977 a reforma integral do Capítulo V do Titulo II da Consolidação das Leis do Trabalho, relativo à segurança e medicina do trabalho, acabou por reconhecer nova modalidade de ação coletiva ao atribuir aos sindicatos legitimidade para postular o reconhecimento da insalubridade ou da periculosidade existente no local de trabalho, com a cobrança dos valores correspondentes. 
As ações coletivas em sentido estrito, reclamações trabalhistas interpostas por sindicatos na qualidade de substituto processual da categoria ou dos associados sem a necessidade de outorga de procuração ou autorização individual, passam a ser admitidas no direito processual do trabalho, para a obtenção dos efeitos pecuniários decorrentes do trabalho perigoso ou insalubre. Contudo, é importante observar que muitos anos se passaram para que o Judiciário admitisse tratar-se de substituição processual, e não representação sindical com necessidade de autorização individual. Muitos juristas, apegados a uma visão tradicional de processo, exigiam autorização individual dos associados para que o sindicato pudesse demandar coletivamente. Dez anos foram necessários até que a matéria fosse sumulada pelo Tribunal Superior do Trabalho, que em 1988 reconheceu ser legítima a substituição processual dos empregados associados, ainda que de forma limitada, e em 1997 suprimiu a limitação aos associados.

\subsection{Redemocratização e Constituição}

O dinamismo político e o protagonismo dos movimentos de trabalhadores no Brasil dos anos 1980, embalados pelas lutas por democracia, autonomia e liberdade sindical também repercutiram nas postulações coletivas perante o Judiciário. Os sindicatos combinavam os instrumentos de autotutela (como greves e manifestações) com os recursos judiciais.

Em paralelo ao aumento do número de greves, na segunda metade dos anos 1980, houve um crescimento absoluto do número de dissídios coletivos interpostos no Brasil. Mas além do crescimento destes tradicionais processos de solução de conflitos de interesse, o sindicalismo tentava inovar em suas práticas judiciais. Embalado pela possibilidade de ampliação da legitimidade ativa, utilizaria a arena judicial (não estamos nos referindo à atuação através da instância normativa dos tribunais trabalhistas) em uma perspectiva de politização de demandas.

Novas modalidades de utilização de mecanismos processuais existentes (como a representação e a substituição processual dos interesses da categoria) passaram a ser colocadas em prática simultaneamente à mobilização direta, canalizando para o Judiciário demandas inéditas que pleiteavam reparações e indenizações em decorrência dos prejuízos causados com os expurgos dos planos econômicos (prejuízos passados e futuros).

A legislação de política salarial (à época introduzida pela Lei 6.708, de 30 de 1979) previu a possibilidade de o sindicato postular as diferenças salariais 
devidas a seus associados, independentemente da necessidade de autorização. A regra foi mantida integralmente na revisão da política salarial ocorrida com a Lei 7.238, de 29 de outubro de 1984. Após a admissão da legitimidade da própria entidade sindical estar em juízo para obter o ressarcimento de vantagens legalmente estabelecidas no que concerne a diferenças salariais apenas para os associados, no final da década seguinte o mecanismo seria ampliado, pois além da Constituição, outras regras infraconstitucionais especificavam tal legitimidade, sem restrições temáticas. As ações coletivas se alargariam - seja pelo conteúdo das postulações, seja pelo instrumento procedimental utilizado - e trariam novos desafios à Justiça do Trabalho.

Para além dos clássicos dissídios coletivos (de interesse e de direito), o Judiciário (em particular o conjunto da Justiça do Trabalho e não mais somente os grupos restritos de Juízes e Ministros que apreciavam os dissídios) seria chamado a participar do controle das políticas públicas em ações judiciais interpostas por sindicatos e associações. Assim como a judicialização não é um tema novo no mundo do trabalho, demandas coletivas visando ao controle das políticas públicas pelo Judiciário também têm suas origens no movimento de trabalhadores. Afinal, as políticas de estabilização econômica são objeto de inéditas contestações coletivas no Judiciário trabalhista, e se tornaram prática corrente entre os Planos Cruzado (1986) e Real (1985).

Assim, durante a década de 1980 a Justiça do Trabalho já recebia inúmeras ações coletivas movidas por sindicatos, denominadas reclamações trabalhistas, na qual postulavam pagamentos de reajustes salariais, adicionais de periculosidade e de insalubridade e também a preservação do valor do salário pelo pagamento dos percentuais de reajustamento salarial suprimidos por leis com novos planos econômicos.

Ações coletivas requerendo o reajustamento dos salários em $26,06 \%$ no caso do Plano Bresser, e em 26,05\%, no caso do Plano Verão - além de serem representativas dos desafios com os quais a Justiça do Trabalho iria se defrontar e assumir ao longo da década de 1990 - indicavam uma combinação inédita de estratégias sindicais.

A capacidade de estar em juízo para a defesa dos interesses de sua categoria é um elemento importante e fundamental para a ação sindical e para a efetividade do próprio Direito do Trabalho, mormente em um sistema legislado. Dessa forma, é relevante o fato de que em paralelo ao ressurgimento das manifestações de conflito coletivo, as ações coletivas tenham sido paulatinamente ampliadas, não sem intensa polêmica judicial e restrições jurisprudenciais. 
No contexto de ressurgimento do movimento sindical foram ampliadas as hipóteses de coletivização no processo do trabalho, com as Leis 6.708, de 30 de outubro de 1979; 7.238, de 29 de outubro de 1984; 7.788, de 1989, culminando com a Lei 8.073, em 30.7.1990. Tais regras, em suas origens, versavam sobre reajustamento salarial.

Todavia, eram múltiplas as questões coletivas levadas ao Judiciário. Além das clássicas ações coletivas presentes na CLT (para postular insalubridade e periculosidade, por exemplo), em determinados setores econômicos ou empresas estatais nas quais a perspectiva de rescisão unilateral por parte do empregador era pequena, as controvérsias seriam encaminhadas pelos sindicatos ao Judiciário, através de ações individuais plúrimas. Tais modalidades de "demandas coletivas" que, do ponto de vista do processo, correspondem a uma ação individual (pois o litigante é o indivíduo, titular do direito material), foram utilizadas no período anterior à Constituição em segmentos econômicos nos quais a perspectiva de dispensa era reduzida.

Em seus estudos sobre a atuação do novo sindicalismo em Volta Redonda, Wilma Mangabeira (1993) registra a modificação na forma de utilização do poder Judiciário na prática concreta dos sindicalistas renovadores durante a década de 1980. Ao contrário do que se poderia supor, Mangabeira conclui que a “maneira como os sindicatos do 'novo sindicalismo' fizeram uso da Justiça do Trabalho não só expandiu os direitos concedidos pela CLT, como criou procedimentos politicamente significativos - o reconhecimento da lei como importante canal de ampliação dos direitos de cidadania e a tentativa de legalizar (normalizar) essa inovação política". Apesar do descrédito e da cautela que a autora percebeu nos sindicalistas em relação ao Judiciário, observou um processo de rediscussão das funções do Departamento Jurídico da entidade sindical pesquisada, através da análise do crescimento das demandas trabalhistas individuais e plúrimas movidas contra a Companhia Siderúrgica Nacional no ano de 1987. Cominava-se o recurso ao sistema Judiciário com a mobilização dos trabalhadores, contrariando práticas usuais na antiga liderança, considerada burocrática. Por essa nova estratégia, o recurso à Justiça não é usado como meio de amortecer as queixas dos operários e desviar o conflito para um foro distante. Ao contrário, o sistema Judiciário torna-se um dos vários canais através dos quais busca-se melhorar e modificar as condições de trabalho, ao mesmo tempo em que se transforma em mecanismo de mobilização e organização (Mangabeira, 1993, p.186). Em contraposição a algumas práticas mais tradicionais no sindicalismo, a expansão do novo sindicalismo, naquele contexto 
de democratização, segundo Mangabeira, teria possibilitado não somente a revelação dos paradoxos entre o legal e o legítimo, bem como a expansão dos direitos e criação de novos direitos (Mangabeira, 1993, p.75).

A Justiça do Trabalho, paulatinamente, se transformava em uma das arenas para as lutas de um sindicalismo renovado, não com o objetivo de substituir a luta política pela ação judicial, mas de conquista e redefinição dos direitos, e de mobilização adicional dos trabalhadores. Na década de 1980, a vivacidade do movimento sindical, que se reorganizara em um contexto de redemocratização política e forte instabilidade econômica, não seria sentida apenas através da explosão do número de greves, de grevistas e de jornadas perdidas de trabalho. Podemos verificar um aumento no número de processos de dissídios coletivos ajuizados no país (principalmente durante o governo Sarney), assim como um crescimento das negociações coletivas de trabalho (Silva, 2008). Apesar desse aumento, em março de 1988 o Tribunal Superior do Trabalho afirmaria seu posicionamento de que as convenções e acordos descumpridos pelos empregadores não poderiam ser objeto de cobrança coletiva pelos sindicatos por via de ações de cumprimento.

$\mathrm{O}$ movimento de alargamento dos instrumentos processuais para a garantia dos direitos não se restringia ao mundo do trabalho, tendo desaguado no congresso constituinte aspirações em torno de mecanismos coletivos para a concretização dos direitos constitucionalmente previstos e de proteção da cidadania como um todo. O Ethos de participação e ampliação dos direitos estava presente no processo de redemocratização do país e no congresso constituinte.

A Constituição de 1988, apesar da atuação do bloco conservador que se traduziu em fortes restrições às demandas dos setores populares, trouxe consigo um ethos de participação, democracia e ampliação dos direitos. Além dos mecanismos de participação popular no processo legislativo, a Constituição estabeleceu como princípio fundamental o acesso à Justiça e buscou atribuir aos cidadãos e às coletividades um amplo conjunto de garantias constitucionais e mecanismos processuais que permitissem o real acesso à jurisdição. Dentre os instrumentos procedimentais estabelecidos pelo constituinte com o objetivo de dar efetividade aos direitos dos trabalhadores, e para a defesa ampla de seus interesses, devemos citar o reconhecimento da legitimidade ativa dos sindicatos para impetrar o mandado de segurança coletivo contra omissão ou ato ilegal ou abusivo praticado por autoridade (CRFB, Art. $5^{\circ}$, inciso LXX, b); a legitimidade ativa reconhecida 
para toda e qualquer associação, inclusive as profissionais, criada há mais de um ano e com a autorização de seus integrantes para representá-los em juízo (CRFB, inciso XXI do artigo $5^{\circ}$ ); e a substituição processual reconhecida aos sindicatos pelo inciso III do artigo $8^{\circ}$ da Constituição ao estabelecer que cabe às entidades sindicais a "defesa dos direitos e interesses coletivos ou individuais da categoria, inclusive em questões judiciais ou administrativas".

E no âmbito específico dos dissídios coletivos houve uma ampliação (no plano constitucional) do poder normativo da Justiça do Trabalho.

\subsection{A década perdida}

Os Anos 1990, do ponto de vista dos direitos e da concretização da Constituição, foram anos perdidos. Enquanto em outros setores do Judiciário a coletivização dos interesses gerou uma inédita corrida à Justiça, em fenômeno designado como de judicialização da política e das relações sociais, no âmbito da Justiça do Trabalho houve uma interpretação extremamente limitadora das possibilidades de ajuizamento de ações coletivas, que cerceavam a defesa pelos sindicatos, dos direitos dos trabalhadores. Em trabalho anterior, examinamos como a jurisprudência trabalhista nos anos 1990 diminuiu os recursos de ação sindical, seja com a restrição dos dissídios coletivos, seja com o não reconhecimento de que a Constituição de 1988 introduzira uma ampla substituição processual para os integrantes das categorias profissionais (Silva, 2008). De início, é importante sublinhar que, embora inicialmente tenha o Judiciário acolhido em parte os pleitos das milhares de ações coletivas ajuizadas pelos sindicatos no final dos anos 1980 e início dos 1990 versando sobre planos econômicos, posteriormente os Enunciados que os asseguravam foram revogados, criando frustração em inúmeras categorias.

Em paralelo ao debate em torno do mérito das ações coletivas visando à reparação dos relevantes prejuízos salariais sofridos pelos trabalhadores, a Justiça do Trabalho enfrentava a polêmica em torno do alcance do artigo $8^{\circ}$, inciso III da Constituição Federal de 1988, bem como das leis ordinárias que consolidavam as prerrogativas processuais dos sindicatos.

Nos primeiros cinco anos de Constituição, advogados de empresas e de sindicatos dos trabalhadores esgrimiram argumentos, petições, sustentações e artigos doutrinários em torno da exegese do inciso III, do Artigo $8^{\circ}$ da CRFB. 
Em 1993, tal polêmica foi resolvida em desfavor dos sindicatos, na batalha que culminou com a edição do Enunciado ${ }^{\circ} 310$, do Tribunal Superior do Trabalho.

Do ponto de vista da atuação coletiva dos Sindicatos, a edição do Enunciado 310 é um marco tão expressivo quanto as condenações dos petroleiros na greve de 1995. Praticamente bloqueou o acesso à Justiça do Trabalho para a defesa dos direitos coletivos por parte das entidades sindicais, afirmando que "o art. $8^{\circ}$, inciso III, da Constituição da República não assegura a substituição processual pelo sindicato." Tal orientação se espraiou pelo Judiciário Trabalhista, sendo acolhida pela amplíssima maioria dos juízes, obstando a legitimidade ativa dos sindicatos para atuarem como substitutos processuais dos integrantes de sua categoria em reclamações trabalhistas. Como observa Rodrigo Carelli, "o interesse em restringir o acesso à Justiça fica mais ainda evidente com a previsão de inexistência de honorários advocatícios nas poucas causas em que admite a substituição processual pelos sindicatos, enfraquecendo a defesa jurídica dos sindicatos" (2011, p.116).

A postulação dos sindicatos perante a Justiça do Trabalho permaneceria extremamente limitada durante toda a década de 1990, tendo praticamente sido fechadas as possibilidades de pleitos coletivos em reclamações trabalhistas. Todavia, pouco a pouco, outro ator institucional de relevância entraria em cena para a defesa dos interesses e direitos coletivos dos trabalhadores no mundo do trabalho: o Ministério Público do Trabalho - MPT. A reconfiguração do Ministério Público do Trabalho e o manejo da ação civil pública pelos sindicatos desafiam a fragmentação dos interesses e a individualização pulverizada dos litígios em juízo. Cássio Casagrande (2008) afirma que as ações civis públicas ajuizadas pelo Ministério Público têm grande importância para os "indivíduos dominados" pois evidencia a afirmação dos seus direitos e a inclusão no sistema político. Casagrande não desconhece os argumentos contrários à atuação do Ministério Público do Trabalho e busca refutá-los ao afirmar que

é preciso ter em mente que no atual regime constitucional o Ministério Público é apenas um dos caminhos que se abrem na luta política dos indivíduos e grupamentos sociais. Este caminho não obstrui outras vias de acesso à jurisdição e ao sistema representativo. Além disso, a atuação do Ministério Público não importa em "formas de controle", nem da vida associativa, nem das reivindicações. (Casagrande, 2008, p.282) 


\section{REFORMA E RECONSTRUÇÃO}

Quanto às ações coletivas e no que concerne às relações entre sindicatos e Justiça do Trabalho, é possível afirmar que os últimos 10 anos foram de reconstrução da jurisprudência em torno das ações coletivas, em paralelo com as modificações na competência e atribuições da Justiça do Trabalho.

Tal processo, ainda em curso, foi de lenta dissensão nas ultrapassadas concepções sobre o processo coletivo. Em 2000, o Tribunal Superior do Trabalho acabaria reconhecendo a legitimidade dos sindicatos para interpor ações de cumprimento postulando a observância das normas e convenções negociadas coletivamente, com a reforma do Enunciado da Súmula 286.

Em 2003, o Tribunal Superior do Trabalho iniciou a revisão de sua jurisprudência em matéria de direitos coletivos, no bojo da mudança presidencial e da assunção de Francisco Fausto à Presidência da Corte. A Instrução Normativa $\mathrm{n}^{\mathrm{o}}$ 04, com restrições ao ajuizamento dos dissídios, foi revogada e $\mathrm{o}$ Enunciado 310 cancelado. A modificação do Enunciado foi fruto de uma combinação de fatores políticos, institucionais e também legais e jurisprudenciais. No voto do Relator, o Tribunal Superior do Trabalho afirma que: "21. O Poder Judiciário do Trabalho vem resistindo a acolher a figura da substituição processual porque está inseguro quanto ao procedimento e quanto às consequências decorrentes de tal acolhimento. A ausência de procedimento atemorizou toda uma geração de juristas, que se ocuparam do tema, e com razão. (...) 22. A Justiça do Trabalho não pode voltar as costas ao que há de mais adequado e moderno para a solução de problemas sociais, entre os quais avulta o caráter individualista de suas demandas em cotejo com a massificação das lesões, estimulando a conflitualidade individualizada que, absurdamente, já chegou a dois milhões de ações anuais." (BRASIL, TST-E-RR-175.894/95.9)

O reconhecimento da legitimidade ativa dos sindicatos foi uma modificação substancial no comportamento de um Tribunal preocupado em se apresentar afinado a uma nova conjuntura. A revogação do Enunciado da Súmula 310 abriu o Judiciário às reclamações coletivas propostas pelas entidades sindicais, que voltaram a poder manejar, agora com maior segurança jurídica, reclamações trabalhistas para a defesa dos interesses individuais homogêneos e coletivos das suas categorias.

É importante sublinhar que a abertura do Tribunal às demandas coletivas (não sem disputas internas, restrições e dificuldades específicas) se deu em um contexto de expansão das ações perante a Justiça do Trabalho, em um ambiente 
de flexibilização dos direitos, de expansão da terceirização e precarização das condições laborais. Em dezembro de 2004, a reforma do Judiciário - promovida pela Emenda Constitucional n ${ }^{\circ} 45$ - reconfigurou a Justiça do Trabalho, com a ampliação da competência para apreciar questões até então submetidas a outros ramos, tais como disputas em torno da representação sindical, lides sindicais, reparação de danos por acidentes de trabalho, ao mesmo tempo em que limitava os dissídios coletivos de natureza econômica às hipóteses de comum acordo.

Nos primeiros cinco anos de vigência da Reforma do Judiciário, 12.014 Ações Civis Públicas - ACPu - foram recebidas na Justiça do Trabalho, sendo que em termos absolutos as Varas do Trabalho que mais receberam ações civis públicas foram as vinculadas aos Tribunais do Rio de Janeiro, São Paulo, Minas Gerais, Rio Grande do Sul, Bahia, Pará e Amapá, Paraná, Distrito Federal e Tocantins, Campinhas e Goiás.

\section{Ações Civis Públicas Recebidas na $1^{\text {a }}$ e $2^{\text {a }}$ Instâncias por Ano. Justiça do Trabalho 2005 a 2010}

\begin{tabular}{|c|c|c|c|c|c|c|}
\hline & 2005 & 2006 & 2007 & 2008 & 2009 & 2010 \\
\hline \multicolumn{7}{|l|}{$1^{\text {a }}$ Instância } \\
\hline $1^{\mathrm{a}}-\mathrm{RJ}$ & 78 & 180 & 155 & 153 & 219 & 192 \\
\hline $2^{a}-S P$ & 124 & 217 & 171 & 204 & 164 & 210 \\
\hline $3^{a}-M G$ & 48 & 104 & 127 & 170 & 145 & 192 \\
\hline $4^{a}-R S$ & 36 & 71 & 116 & 238 & 282 & 212 \\
\hline $5^{\mathrm{a}}-\mathrm{BA}$ & 46 & 54 & 78 & 136 & 141 & 140 \\
\hline $8^{\mathrm{a}}-\mathrm{PA}$ e AP & 44 & 109 & 86 & 81 & 85 & 88 \\
\hline $9^{a}-P R$ & 46 & 94 & 162 & 168 & 319 & 309 \\
\hline $10^{\mathrm{a}}-\mathrm{DF}$ e TO & 178 & 56 & 42 & 81 & 81 & 9 \\
\hline $15^{\mathrm{a}}-$ Campinas & 49 & 121 & 113 & 381 & 246 & 259 \\
\hline $18^{\mathrm{a}}-\mathrm{GO}$ & 35 & 64 & 61 & 73 & 62 & 620 \\
\hline TOTAL GERAL & 1.005 & 1.534 & 1.549 & 2.427 & 2.426 & 3.073 \\
\hline
\end{tabular}

Fonte: Elaboração da autora com base em dados fornecidos pela Coordenadoria de Estatística e Pesquisa do TST - Em 12/04/2011

A coletivização das demandas, entretanto, pode ser ainda maior, na medida em que os sindicatos podem propor outras modalidades de ações (Reclamações Trabalhistas, Ações de Cumprimento etc.), não havendo registros estatísticos do número de casos interpostos por entidades sindicais na Justiça do Trabalho. 
Em relação a questões sindicais submetidas à Justiça do Trabalho após a reforma do Judiciário, observe-se que quanto às ações de cobrança de contribuição sindical, foram recebidas 73.689 ações na primeira instância da Justiça do Trabalho (e classificadas como tal, para efeitos de mensuração). Todavia, em vez de uma tendência de crescimento, a partir de 2007 houve uma substancial queda no número de ajuizamentos deste tipo de ação (somente 1.978 em 2010). Foram 842 as ações classificadas como disputa de representação sindical recebidas entre 2005 e 2010 na primeira instância da Justiça do Trabalho, número significativo considerando-se o total de sindicatos registrados no país.

O número de dissídios coletivos, por sua vez, representa praticamente um terço das ações civis públicas, pois no mesmo período foram recebidos 4.413 dissídios nos Tribunais Regionais. Um pouco mais de 1/5 envolvem dissídios coletivos de greve, que totalizaram 951, segundo classificação e registros existentes na Coordenadoria de Estatística e Pesquisa do TST.

Dissídios Coletivos Recebidos na $2^{\mathrm{a}}$ Instância por Ano. Justiça do Trabalho 2005 a 2010

\begin{tabular}{lcccccc}
\hline & 2005 & 2006 & 2007 & 2008 & 2009 & 2010 \\
Total de Dissídios Coletivos recebidos & 578 & 606 & 872 & 849 & 764 & 744 \\
$\begin{array}{l}\text { nos Tribunais Regionais do Trabalho } \\
\text { Total de Dissídios Coletivos de Greve }\end{array}$ & 134 & 131 & 96 & 139 & 231 & 200 \\
\hline
\end{tabular}

Fonte: Elaboração da autora com base em dados fornecidos pela Coordenadoria de Estatística e Pesquisa do TST em 12/04/2011

Conflitos em torno do relevante tema da dispensa coletiva foram apreciados pela Justiça do Trabalho pela via dos dissídios coletivos. Segundo estudo de Pessanha, Alemão e Soares (2009), no contexto da crise econômica de 2008/2009 e de despedidas coletivas promovidas por determinados grupos econômicos, tais como a Embraer e a Companhia Siderúrgica Nacional, entidades sindicais diversas lançaram mão de estratégias para a defesa do emprego, que envolveram o recurso a dissídios coletivos de natureza jurídica, "utilizados como via estratégica de procedimentalização do direito". Se nos últimos anos, o Judiciário teve sua clássica prerrogativa normativa limitada, por outro lado, para Pessanha, Alemão, Soares, a Justiça do Trabalho se 
abriria novamente para apreciar demandas coletivas, não somente as oriundas do Ministério Público do Trabalho, como também as originárias dos entes sindicais na defesa de interesses e direitos coletivos (Pessanha, Alemão, Soares, 2009, p.87).

Para melhor compreensão das lides coletivas que têm sido apreciadas nos últimos anos, apresentaremos algumas decisões proferidas em Ações Civis Públicas e relatos de casos selecionados.

Em sua tese sobre os direitos fundamentais no mundo do trabalho, Rodrigo Carelli apresenta seis exemplos de atuação do Ministério Público do Trabalho MPT em casos envolvendo: a) adicional de periculosidade, b) banco de horas e assédio moral, c) prática de atos antissindicais, d) degustadores de cigarro, e) demissão em massa f) intermediação de mão de obra no corte de cana-deaçúcar, g) descontos salariais dos trabalhadores (2011, p.162-216). Ilustrativos da multiplicidade das controvérsias submetidas ao Judiciário Trabalhista merecem ser apresentados, realçando como chegaram ao conhecimento do MPT.

No caso do banco de horas, o MPT agiu após denúncia do Sindicato dos Trabalhadores e de investigação realizada na empresa Big Foods. Tratase da utilização do banco de horas sem participação do sindicato dos trabalhadores, pressão para realização de horas extras, com ameaças, xingamentos e ofensas morais, pressão por produtividade e acidentes de trabalho, temas levados ao Judiciário por meio de ACPU (Carelli, 2011, p.166). Em outro episódio, o MPT também agiu em consonância com os interesses dos trabalhadores reconhecidos nas negociações coletivas, ao firmar Termo de Compromisso impedindo à empresa de segurança de promover descontos salariais dos empregados devido à subtração criminosa de objetos por terceiros nos postos de serviços, consoante previsão anterior em convenção coletiva. Como observa Carelli, foram protegidos os direitos fundamentais e "mais interessante ainda, realizou-se a defesa de um dispositivo constante em norma coletiva autônoma criada pelos sindicatos. Assim, além de se defender a aplicação (e legitimidade) da lei, buscou-se justificar a própria norma criada pelos atores sociais e descumprida pela empresa" (2011, p.180).

A despedida coletiva de 500 trabalhadores promovida pela Companhia Siderúrgica Nacional em 2008 também foi objeto de ação civil pública proposta pelo MPT após denúncia do Sindicato dos Metalúrgicos. O Sindicato recorreu ao MPT depois de tentativa de negociação direta com a empresa e intervenção 
da prefeitura municipal, atos infrutíferos (Carelli, 2011, p.202-208). Nas ocorrências em que o Ministério Público age instado pelo Sindicato profissional ou defendendo a atuação sindical, protegendo direitos fundamentais, estaria a demonstrar uma releitura. Para o professor, o Direito do Trabalho, que "sempre dependeu da relação de forças do capital e do trabalho, passa a encontrar suas forças externamente a essa luta, mas internamente no próprio Direito e nos princípios ético-morais previstos nos tratados e na Lei Fundamental" (2011, p.208-209).

Ações oriundas de investigações instauradas de ofício pelos próprios integrantes do Ministério Público também são comuns. Nos casos referência selecionados por Carelli, a Ação Civil Pública que postula a reparação dos danos causados aos trabalhadores teve inicio quando jornalistas entrevistaram a Procuradora Chefe para reportagem sobre danos causados à saúde pela indústria do tabaco. Os empregados que labutavam no "Laboratório de Avaliações Sensoriais" de companhia brasileira eram usados como dispositivos de medida em experimentações sensoriais com provas de cigarro. Uma paralisação coletiva de 150 trabalhadores no corte de cana, ocorrida em São Paulo, motivou a fiscalização nas plantações de uma usina por parte de auditores-fiscais e procuradores do trabalho. Foi apurada a ocorrência de terceirização ilícita, precariedade nas condições sanitárias e de moradia, desconformidade nos equipamentos de proteção individual e de valores pagos aos trabalhadores. Diante da frustração do termo de ajuste de conduta, o MPT ingressou com a ação civil pública (Carelli, 2011, p.209216).

A tese de que o Ministério Público do Trabalho age como um representante funcional dos trabalhadores, sem substituir as outras entidades de representação e convivendo em parceria com as instituições de representação para a sociedade, encontra eco nos relatos acima. Entretanto, outras hipóteses de intervenção, também estudadas pelo autor, demonstram como pode ser mais complexa a relação entre MPT e Sindicatos, mormente quando o Ministério Público age por provocação de integrantes do próprio Judiciário e em sua atuação se opõe a outras instituições de defesa dos trabalhadores, como os sindicatos.

Na Ação Civil Pública 01399-2000-028-01-00-4, o Ministério Público requer seja declarado ilícito o pagamento de adicional de periculosidade, ainda que de forma indireta, aos empregados da Petrobrás que não estivessem exercendo atividades junto a substâncias inflamáveis, explosivas ou com energia 
elétrica, bem como para impedir que a empresa estendesse tal adicional a trabalhadores que não se encontrassem nas hipóteses legais de recebimento. Carelli informa que a investigação do Ministério Público teve início com representação do Juiz do Trabalho que presidia a $42^{a}$ Vara do Rio de Janeiro, a partir de julgamento em reclamação individual na qual arquivistas e escriturários da estatal pleiteavam recebimento isonômico. Na ação, a defesa da Petrobrás alegava que a extensão do direito ao pagamento do adicional a todos os trabalhadores decorrera da "pressão exercida pelos sindicatos representativos da categoria dos petroleiros que, nos idos de 1961/1962, possuíam considerável poder de reivindicação, tendo em vista o momento político que atravessava o país. Assim, sucessivos acordos coletivos foram celebrados com cláusula específica dispondo sobre este benefício" (Apud Carelli, 2011, p.163). Os argumentos do MPT sobre o patrimônio público e a probidade administrativa são características da atuação mais tradicional do Ministério Público, para demonstrar a complexidade da sua atuação no mundo do trabalho.

O cumprimento de direitos relacionados à limitação da jornada de trabalho também vem sendo objeto de inúmeras ações coletivas. Consoante recente notícia divulgada pelo Tribunal Regional do Trabalho da $1^{\text {a }}$ Região, liminar determina que a Cooperativa dos Motoristas de Táxi do Horto Florestal se abstenha de prorrogar a jornada de trabalho de seus empregados além das duas horas diárias. O Ministério Público constatou, em inquérito civil, que a cooperativa impõe uma jornada de trabalho excessiva: empregados, "como as telefonistas, chegavam a trabalhar 18 horas por dia, além de serem vigiados por câmeras de segurança ininterruptamente, o que limitava sua liberdade de expressão." Registre-se que a categoria diferenciada das telefonistas detém jornada especial reduzida.

A utilização de ações civis públicas para exigir o cumprimento da jornada de trabalho tem propiciado um alargamento do próprio direito material em discussão, com o reconhecimento de que velhas práticas ilícitas presentes em segmentos do mercado de trabalho brasileiro, como por exemplo, a de impedir o registro da real jornada laborada para frustrar o regular pagamento das horas extraordinárias, geram danos morais coletivos. É o que se deduz de casos em que empresas dos setores bancário e comerciário foram condenadas pelo Tribunal Superior do Trabalho.

SCIENTIA IURIS, Londrina, v.16, n.2, p.29-56, dez.2012 


\section{CONCLUSÃO}

E o que nos parece mais singular é a possibilidade de adequada contextualização de práticas empresariais de violação de bens extrapatrimoniais e abuso moral contra trabalhadores. Enquanto nas lides individuais a delimitação acaba resvalando para uma compreensão das ocorrências como fenômenos patológicos ou intersubjetivos (danos morais por assédio de chefes perseguidores ou maus administradores), a postulação por meio de ações civis públicas permite concluir que práticas vexatórias, humilhantes e abusivas podem ser características do próprio modo de gestão empresarial no capitalismo contemporâneo.

Há fortes elementos, pois, que nos permitem concluir que a renovação jurisprudencial do Direito do Trabalho brasileiro no último quinquênio se relaciona com o redesenho institucional promovido com a ampliação da competência da Justiça do Trabalho, a uma abertura maior do Judiciário às demandas coletivas, à atuação dos Sindicatos e do Ministério Público do Trabalho. Com a coletivização dos interesses e a reabertura do processo à atuação das representações dos trabalhadores, o Direito e a Justiça do Trabalho podem se renovar. Todavia, fica o alerta de que "obstáculos, internos e externos, existem para que a Justiça do Trabalho seja local pleno de fruição de direitos" (Carelli, 2011, p.117).

\section{REFERÊNCIAS}

ACKER, Ana. Poder Normativo e regime democrático. São Paulo: Ltr, 1986.

ALVIM, Joaquim Leonel. A memória da justiça do trabalho: história do percurso de uma pesquisa. Revista de Direito Mackenzie, São Paulo, 2003. Ano 04, Número 01.

ALVIM, Joaquim Leonel. O Paradigma Procedural do Direito: traduções da teoria para o Direito do Trabalho e Jurisprudência Trabalhista. São Paulo: LTr, 2006. v.1.

ALVIM, Joaquim Leonel, FRAGALE FILHO, Roberto. Justiça do Trabalho: um paradigma em crise? Trabalho \& Doutrina, São Paulo, 1999, v.21, p.113-126. 
ALVIM, Joaquim Leonel; JEAMMAUD, Antoine, FRAGALE FILHO, Roberto. Trabalho, Cidadania \& Magistratura. Rio de Janeiro: Edições Trabalhistas, 2000. v.1.

ARTUR, Karen. O TST frente à tercerização. São Carlos: EDUFSCar/ FAPESP, 2007.

ARTUR, Karen. O novo poder normativo do TST: dissídios individuais e atores coletivos (Tese de Doutorado). São Carlos: UFSCar, 2010, Disponível em $<$ http://www.bdtd.ufscar.br/htdocs/tedeSimplificado//tde_busca/ arquivo.php?codArquivo=3709> Acesso em 09. mar. 2011.

BAHIA. Tribunal Regional do Trabalho da $5^{\text {a }}$ região, $4^{\text {a }}$ Turma. Proibição ao uso de barba no trabalho. Inexistência de dano moral coletivo. Recurso Ordinário $n^{\circ}$ 0073200-78.2008.5.05.0007. Recorrente: Ministério Público do Trabalho e Banco Bradesco S.A.Recorridos: Banco Bradesco S.A. e Ministério Público do Trabalho. Relatora: Desembargadora Graça Boness. Salvador, Bahia, 06 jul. 2011. Disponível em: <http://www.trt5.jus.br/ consultaprocessos/modelo/ consulta_documento_blob.asp?v_id=AAAbOCADDAACOYmAAU\&fb_source-message $>$. Acesso em 18. Mar. 2012.

BRASIL. Tribunal Superior do Trabalho. Enunciado $\mathbf{n}^{\mathbf{0}} \mathbf{1 8 0}$. Ação de Cumprimento. Substituição Processual. Desistência (cancelada) - Res. 121/ 2003, DJ 19, 20 e 21.11.2003. Disponível em: <http://www3.tst.jus.br/ jurisprudencia/Sumulas_com_indice/Sumulas_Ind_151_200.html\#SUM180>. Acesso em: 25 mar. 2012.

BRASIL, Tribunal Superior do Trabalho. Enunciado No 255. Substituição Processual. Desistência. Disponível em: $<$ http://www3.tst.jus.br/ jurisprudencia/Sumulas_com_indice/Sumulas_Ind_251_300.html\#SUM255>Acesso em: 19 mar. 2012 .

BRASIL. Tribunal Superior do Trabalho. Enunciado n ${ }^{0}$ 271. Substituição Processual. Adicionais de insalubridade e de periculosidade. Cancelado pela Res. 121/2003, DJ 21.11.2003. Disponível em: <http://www3.tst.jus.br/ jurisprudencia/Sumulas_com_indice/Sumulas_Ind_251_300.html\#SUM271>. Acesso em: 19 mar. 2012 
BRASIL. Tribunal Superior do Trabalho. Enunciado n 310. Substituição Processual. Sindicato (cancelamento mantido) - Res. 121/2003, DJ 19, 20 e 21.11.2003 e republicada DJ 25.11.2003. Disponível em: $<$ http:// www3.tst.jus.br/jurisprudencia/Sumulas_com_indice/ Sumulas_Ind_301_350.html\#SUM-310>. Acesso em: 25 mar. 2012. BRASIL. Tribunal Superior do Trabalho. Orientação Jurisprudencial SDI N. 121. Substituição processual. Diferença do adicional de insalubridade. Legitimidade (Inserida em 20.11.97). Disponível em: $<$ http://www3.tst.jus.br/ jurisprudencia/OJ_SDI_1/n_s1_121.htm\#TEMA121> Acesso em: 19 mar. 2012.

BRASIL. Tribunal Regional do Trabalho da $\mathbf{1}^{\text {a }}$ Região. MPT OBTÉM TUTELA ANTECIPADA PARA LIMITAR JORNADA. Disponível em: < http://portal2.trtrio.gov.br:7777/pls/portal/

PORTAL.wwv_media.show?p_id=14254778\&p_settingssetid $=381905 \& p$ settingssiteid $=73 \& p \_$siteid $=73 \& p \_$_type $=$basetext\&p_textid $=14254779>$. Acesso em: 20 mar. 2012.

BRASIL. Tribunal Superior do Trabalho. Quinta Turma. Relator Desembargador Luiz Otávio Linhares Renault. TRT 00177-2007-105-03-00-4 RO 12.06.2007. Minas Gerais: 2007.

BRASIL. Tribunal Regional do Trabalho da $21^{\text {a }}$ Região. Recurso Ordinário ${ }^{\circ}$ 01034-2005-001-21-00-6 - TRT 21 ${ }^{\text {a }}$ Região - Origem: $1^{\text {a }}$ Vara do Trabalho de Natal/RN. Disponível em: http://www.assediomoral.org/spip.php?article316. Acesso em 25 jun. 2011.

BRASIL. Tribunal Regional do Trabalho da $3^{\text {a }}$ Região. Terceira Turma. Relatora Juíza Cristina Diniz Caixeta. 01490-2003-002-03-00-9-RO. 28.0.2004. Minas Gerais: 2004. Disponível em: http://as1.trt3.jus.br/consulta/ detalheProcesso1_0.htm?conversationId=1578967. Acesso em: 25 jun. 2011.

CAMARgO, J. M. Reforma da legislação trabalhista. Cadernos Adenauer, Rio de Janeiro, v. 3 (sindicalismo e relações trabalhistas), n.2, p.56, jul. 2002.

CARDOSO, Adalberto Moreira. A década neoliberal e a crise dos sindicatos o Brasil. São Paulo: Boitempo, 2003. 
CARDOSO, Adalberto Moreira. Direito do trabalho e relações de classe no Brasil contemporâneo. In: Luiz Werneck Vianna. (Org.). Os três poderes e a democracia no Brasil. Belo Horizonte-Rio de Janeiro: Editora da UFMG: 2002, p.493-555.

CAPPELLIN, Paola. As ocupações de colarinho rosa. Trabalhadoras e empresas de telecomunicação, Rio de Janeiro de 1956 a 1996. AMORJUFRJ, 2012.

CARELLI, Rodrigo de Lacerda. O mundo do trabalho e os direitos fundamentais: o Ministério Público do Trabalho e a representação funcional dos trabalhadores. Porto Alegre, Sérgio Antonio Fabris Ed., 2011.

CASAGRAnDE, Cássio. Ministério Público e a judicialização da política: Estudos de casos. Porto Alegre: Sergio Antonio Fabris Ed, 2008.

COLISTETE, RENATO P. Productivity, Wages, and Labor Politics in Brazil, 1945-1962 http://www.fea.usp.br/feaecon//media/livros/file_221.pdf

D'ARAÚJO, M. C. Estado, classe trabalhadora e políticas sociais. In: FERREIRA, J.; DELGADO, L. A. N. (Org.) O Brasil republicano. O tempo do nacional-estatismo: do início da década de 1930 ao apogeu do estado Novo. Rio de Janeiro: Civilização Brasileira, 2003.

ENGELMANN, Fabiano. Sociologia do campo jurídico: juristas e usos do direito. Porto Alegre: Sérgio Antônio Fabris Ed., 2006.

FARIA, José Eduardo. (Org.). Direito e justiça: a função social do judiciário. São Paulo: Ática, 1989.

FARIA, José Eduardo; CAMPILONGO, Celso. A Sociologia jurídica no Brasil. Porto Alegre: Fabris, 1991.

FARIA, José Eduardo. Justiça e conflito: Os juízes em face dos novos movimentos sociais. 2a. ed. São Paulo: Revista dos Tribunais, 1992. 
FARIA, José Eduardo (Org.). Direitos Humanos, direitos sociais e justiça. 2a. ed. São Paulo: Ed: Malheiros, 1994, v.1.

FARIA, José Eduardo. Os novos desafios da justiça do Trabalho. São Paulo: Ltr, 1995.

FARIA, José Eduardo. O sistema brasileiro de Justiça: experiência recente e futuros desafios. Estudos Avançados (USP.Impresso), São Paulo, v.18, n.51, 2004, p.103-125.

FREITAS, Lígia Barros de. A Política e o TST na Constituição dos Direitos do Trabalho. 1. ed. São Paulo: LTr, 2011, v.1, p.112.

FRENCH, J. D. Afogados em leis: a CLT e a cultura política os trabalhadores brasileiros. São Paulo: Fundação Perseu Abramo, 2001.

GOMES, Ângela de Castro; PESSANHA, Elina Gonçalves da Fonte. Trajetórias de Juízes. Porto Alegre, POA, TRT 4ª 2010.

HORN, Carlos Henrique. Negociações coletivas e poder normativo da Justiça do Trabalho. Revista de Ciência Sociais, Rio de janeiro, vol.49, n.2, p.417-445, 2006.

HORN, Carlos Henrique; TEDESCO, Maria Silvana R. A expansão recente da demanda da Justiça do Trabalho e a distribuição setorial das ações: uma análise exploratória de seus fatores explicativos. Revista de Direito do Trabalho (São Paulo), v.137, p.11-44, 2010.

HORN, Carlos Henrique (Org.); COTANDA, Fernando Coutinho (Org.). Relações de trabalho no mundo contemporâneo: ensaios multidisciplinares. 1. ed. Porto Alegre: Editora da UFRGS, 2011. v.1.848p.

JUNQUEIRA, Eliane. Um diagnóstico da Justiça do Trabalho. Síntese Trabalhista, Porto Alegre, v.10, n.115, p.141-153, 1999. 
LOPES, José Reinaldo Lima. A Função política do poder judiciário. In: José Eduardo Faria. (Org.). Direito e justiça: a função social do judiciário. 1a ed. São Paulo: Ática, 1989, v.1.

MACIEL, Débora Alvez; KOERNER, Andrei. Sentidos da judicialização da política: duas análises. In: Lua Nova, $\mathrm{n}^{\circ}$ 57, 2002, p.123-124. MANGABEIRA, Wilma. Os dilemas do novo sindicalismo: democracia e política em Volta Redonda. Rio de Janeiro: Relume-Dumará: ANPOCS, 1993, p.75, 175 e 186.

NORONHA, Eduardo. Entre a lei e a arbitrariedade: mercado e relações de trabalho no Brasil. São Paulo: Ltr, 2000.

OLIVEIRA, Marco Antonio. Política trabalhista e relações de trabalho no Brasil: da Era Vargas ao Governo FHC. 2002. Tese (doutorado) Instituto de Economia, Universidade Estadual de Campinas, Campinas.

PAESE, Raquel. A Constituição Brasileira de 1988 e a atuação dos sindicatos nos espaços de regulação do trabalho. HORN, Carlos Henrique (Org.); COTANDA, Fernando Coutinho (Org.). In: Relações de trabalho no mundo contemporâneo: ensaios multidisciplinares. 1. ed. Porto Alegre: Editora da UFRGS, 2011. v.1.

PAOLI, Maria Célia. Os direitos do trabalho e sua justiça: em busca de referências democráticas. Revista da USP (Dossiê Judiciário), São Paulo, n.21, p.100-115, mar. / mai.1994.

PESSANHA, Elina; MOREL, Regina. A Justiça do Trabalho, Tempo Social, Revista de Sociologia da USP, v.19, n.2, 2007.

PESSANHA, E. G. F. ; MOREL, R. L. M. Reforma sindical, direitos e justiça do trabalho na visão dos magistrados: algumas reflexões preliminares. Revista de Direitos do Trabalho, São Paulo, v.119, 2005.

PESSANHA, Elina; ALEMÃO, Ivan e SOARES, José Luiz. TST, Dissídios Coletivos, Demissão Massiva: Novos Desafios para a Justiça do Trabalho. 
In: O Mundo do Trabalho, v.1. Leituras críticas da Jurisprudência do Tribunal Superior do Trabalho. Hugo Melo Filho et. al. (Orgs.) São Paulo: LTr, 2009, p.77-94.

PINHEIRO, Arnaldo. Magistrados, judiciário e economia no Brasil. In: ZYLBERSZTAJN, D; SZTAJN, R. (Org.) Direito e economia: análise econômica do Direito e das organizações. Rio de Janeiro: Elsevier, 2005.

SAAD, Eduardo Gabriel et al. Consolidação das Leis do Trabalho Comentada. 37 ed. São Paulo: LTr, 2004.

SILVA, Sayonara Grillo Coutinho Leonardo da. Relações Coletivas de Trabalho: configurações institucionais no Brasil contemporâneo. São Paulo: LTr, 2008.

SILVA, Sayonara Grillo Coutinho Leonardo da. Reforma do Judiciário e Justiça do Trabalho: Esboço para a avaliação do legado reformador no âmbito do direito de greve. In: O que estão fazendo da Nova Competência da Justiça do Trabalho? Análise crítica da jurisprudência do STF, do TST e do STJ após a EC 45/2004. COUTINHO, Grijalbo, FAVA, Marcos Neves (Org.) São Paulo: LTr, 2011, p.611-639.

SÜSSEKIND, A. et al. Instituições do direito do trabalho. 21 ed. v.2, São Paulo: LTr, 2004.

TOLEDO FILHO, Manoel Carlos. El caso Embraer y el ordenamiento brasileño. In: Revista Latinoamericana de Derecho Social, n.11, Disponível em Revistas.unam.mx, 2010.

TREVES, Renato. Sociologia del diritto: origine, ricerche, problemi. Torino: Giulio Einaudi, 1993.

VIANNA, Luiz Werneck; BURGOS, Marcelo T. B; SALLES, Maria Alice. Constitucionalização da legislação do trabalho no Brasil. Brasília: Fundação Astrojildo Pereira, 2010. 
VIANNA, Luiz Werneck et al. A Judicialização da política e das relações sociais no Brasil. 1 ed. v.01, Rio de Janeiro: Revan, 1999b.

WEFORT, Francisco. Sindicatos e Política. 1970. Tese (Livre Docência) Faculdade de Filosofia, Letras e Ciências Humana, Universidade de São Paulo.

Recebido em: 2012-11-24

Aprovado para publicação em: 2012-12-17

Como citar:DA SILVA,Sayonara Grilo Continho Leonardo. Justiça do trabalho e demandas coletivas: fragmentos. Scientia Iuris, Londrina, v.16, n.2, p.29-56, dez. 2012. DOI: $10.5433 / 2178-8189.2012$ v16n2p29. 